DOI: http://dx.doi.org/10.18764/2358-4319.v10n2p31-52

\title{
Pressupostos teórico-metodológicos da Educação Física na Educação Infantil
}

Manoel dos Santos Gomes ${ }^{1}$

\section{RESUMO}

Este artigo é um estudo exploratório que utiliza a abordagem qualitativa, sendo seu delineamento bibliográfico/documental. As análises dos documentos e das bibliografias se pautaram na ADTO - análise do discurso teoricamente orientada, referenciada em Norman Fairclough (2001), na realidade, um método que utiliza a interpretação do discurso em três dimensões: como texto, como prática discursiva e como prática social. Os objetivos deste artigo foram: caracterizar quais são as abordagens que direcionam a organização do trabalho pedagógico dos profissionais que atuam nas Instituições de educação infantil (nomeadas como creches e pré-escolas, na LDBEN 9394/96) e demonstrar como estas abordagens influenciam e determinam a prática pedagógica do profissional que trabalha com o componente curricular educação física, nestes espaços.

Palavras-chave: Educação Física. Educação Infantil. Abordagens Metodológicas

\section{Theoretical-methodological assumptions of Physical Education in Early Childhood Education}

\section{ABSTRACT}

This article is an exploratory study that uses the qualitative approach and its bibliographic/documentary design. The analyzes of the documents and bibliographies were based on the ADTO - analysis of the theoretically oriented discourse, referenced in Norman Fairclough (2001), in reality, a method that uses the interpretation of discourse in three dimensions: as text, as discursive practice and as social practice. The objectives of this

1 Doutor em Educação pela Universidade Federal de Santa Catarina. Professor do Curso de Educação Física da Universidade Estadual do Sudoeste da Bahia. E-mail: manoel.gomes@ uesb.edu.br 
article were: to characterize the approaches that guide the organization of the pedagogical work of professionals working in Child Education Institutions (named nurseries and preschools in LDBEN 9394/96) and demonstrate how these approaches influence and determine the pedagogical practice of the professional who works with the physical education curricular component in these spaces

Keywords: Physical Education. Child Education.Methodological Approaches

\section{Presupuestos teórico-metodológicos de la Educación Física en la Educación Infantil}

\section{RESUMEN}

Este artículo es un estudio exploratorio que utiliza el abordaje cualitativo, siendo su delineamiento bibliográfico / documental. Los análisis de los documentos y de las bibliografías se pautaron en la ADTO - análisis del discurso teóricamente orientada, referenciada en Norman Fairclough (2001), en realidad, un método que utiliza la interpretación del discurso en tres dimensiones: como texto, como práctica discursiva y como práctica Social. Los objetivos de este artículo fueron: caracterizar cuáles son los enfoques que orientan la organización del trabajo pedagógico de los profesionales que actúan en las Instituciones de educación infantil (nombradas como guarderías y preescolares, en la LDBEN 9394/96) y demostrar cómo estos enfoques influencian y determinan la práctica pedagógica del profesional que trabaja con el componente curricular educación física, en estos espacios.

Palabras clave: Educación Física. Educación Infantil. Enfoques Metodológicos

\section{Introdução}

A legislação educacional brasileira em relação à educação infantil, pelo menos no que concerne às duas primeiras LDB, não deu à pequena infância a importância que lhe era devida, o que representou uma negligência com uma das fases mais representativas para o processo de desenvolvimento/aprendizagem da criança pequena. Autores como Vygotsky, (2001), Elkonin, (1998), Leontiev, (2002), Wallon (2007) 
definem a educação para a faixa etária entre zero e seis anos como fundamental para o desenvolvimento afetivo, o ato motor e o conhecimento. Na realidade, não levar estes aspectos em consideração indica que aquelas leis de diretrizes foram no mínimo omissas ao sugerir medidas paliativas, ao invés de uma proposta orgânica para a educação infantil.

Note-se que a LDB 4024/61, em seu artigo 23, indicava simplesmente que a educação da criança deveria acontecer nas escolas maternais e jardins de infância, nada mais que isso; enquanto a 5692/71, ancorada no art. $17, \S 2^{\circ}$, esperava que os sistemas de ensino velassem pela educação dos indivíduos abaixo de 7 anos, ou seja, o Estado deixava a cargo de interpretações diversas como deveria ser implementada a educação da pequena infância. Mais grave ainda, provavelmente a interpretação do texto das leis de diretrizes tenha permitido isso, está relacionado ao profissional responsável pela educação da criança nas creches e pré-escolas, era, na sua grande maioria, aquele oriundo dos cursos de magistério, isto é, não havia necessidade de formação superior para organizar o trabalho pedagógico nas instituições de educação infantil, uma exigência fecunda em função do grande arcabouço teórico produzido, principalmente pelos autores citados acima.

Entretanto, este quadro apresenta outras cores, além da cinza, a exemplo da LDB 9394/96, já que esta traz uma concepção orgânica para a educação da criança, ainda que traga o paradoxo de sugerir que profissionais com o ensino médio possam atuar na educação das crianças pequenas, não levando em consideração a luta de diversos pesquisadores, que cobravam a formação superior para atuar neste no nível da Educação. Porém, a grande novidade é a inserção da educação física como um elemento obrigatório no trabalho pedagógico. Contudo, no que se refere a este componente curricular, termina por negar seus conhecimentos ao permitir que qualquer dos profissionais que compõem o corpo docente da creche e pré-escola possa trabalhar os conhecimentos oriundos deste componente curricular. Quem sabe se a medida provisória 746/2016 (que propôs, inicialmente, a retirada da obrigatoriedade da educação física da educação infantil e do ensino fundamental, tornando-a facultativa no ensino médio), não seja a confirmação de que sua permanência neste nível da educação não traga nenhuma contribuição efetiva no processo de aprendizagem/desenvolvimento infantil, já que mesmo sem formação específica a lei sugere que o profissional trabalhe seus fundamentos? 
Este artigo é o primeiro resultado da pesquisa Educação Física na Educação Infantil: revelando a contextura da intervenção profissional, Pós LDBEN 9394/96, nas Instituições de Educação Infantil ${ }^{2}$ em Jequié - Bahia, um estudo de caso, ainda em andamento. Para esta primeira investida, estabeleceram-se como objetivos: caracterizar quais são as abordagens que direcionam a organização do trabalho pedagógico dos profissionais que atuam nas instituições de educação infantil e demonstrar como estas abordagens influenciam e determinam a prática pedagógica do profissional, que trabalha com o componente curricular educação física, nas creches e pré-escolas.

Para o desenvolvimento do estágio inicial da pesquisa recorreram-se a alguns documentos exarados pelo Estado; entre eles, a LDBEN 9394/96, a primeira das diretrizes a estabelecer uma organicidade para educação infantil, definindo claramente as faixas etárias: 0 a 3 e 4 a 5 anos, ao tempo em que definiu, de forma categórica, quais seriam os espaços mais adequados para a realização da educação da pequena infância, no texto da lei, creches e pré-escolas; também utilizou-se o parecer CNE/CEB 016/2001, que versa sobre a obrigatoriedade da educação física como componente curricular da educação básica e sobre a grade curricular do curso de educação física da rede pública de ensino. Por fim, fez-se uma incursão nas bases epistemológicas dos autores discutidos e suas respectivas abordagens.

Trata-se de um estudo exploratório que utiliza a abordagem qualitativa com um delineamento bibliográfico/documental. As análises se ancoraram na ADTO - Análise do Discurso Teoricamente Orientada, referenciada em Norman Fairclough (2001), método que trabalha a interpretação do discurso em três dimensões: como texto, como prática discursiva e como prática social. A escolha da ADTO no desenvolvimento do trabalho se deu por esta conciliar, "com sucesso, a perspectiva de análise centrada nos aspectos da 'textura' dos discursos com os processos de ordem política e ideológica que os constituem" (SHIROMA; CAMPOS; EVANGELISTA, 2004 , p. 12) - nada mais adequado para quem tinha a pretensão de penetrar nos interstícios dos documentos, assim como apresentar as diversas nuances das abordagens metodológicas da educação infantil, porque, ao colocar os documentos sob este crivo, "aprendemos a desconstruí-los para poder interpretá-los e captar pelo avesso alguns aspectos da política

2 Creches e Pré-Escolas, assim são denominadas as Instituições de Educação Infantil na LDBEN 9394/96. 
educacional da qual são expressão, mas que, por diferentes estratagemas, não são aparentes" (SHIROMA; CAMPOS; EVANGELISTA, 2004, p. 13).

Divide-se a trajetória deste ensaio em três movimentos que se entrelaçam formando uma unidade: no primeiro, caracterizamos o objeto, apresentando sua formatação teórico-metodológica; no segundo, expõe-se a contextura em que as análises se fundamentaram, momento em que se insere a tese a ser trabalhada, enquanto no terceiro, desenvolvemo-la, apresentando as tendências percebidas no debate.

Educação física na educação infantil: paradoxos, controvérsias e ambiguidades

Desde a promulgação da última Lei de Diretrizes e Bases da Educação Nacional, LDBEN 9394/96, a educação física não conseguiu elaborar uma proposta com pressupostos teórico-metodológicos articulados e definidos para uma intervenção docente efetiva no nível da educação infantil. Ou seja, quase que deliberadamente, a educação física não se preocupou com a educação da primeira infância. Não deixa de causar estranheza este não comprometimento com o processo de desenvolvimento/aprendizagem da criança pequena.

Mas, é preciso que se diga: esta não é uma situação que deveria passar despercebida por uma área que tem, na formação de professores, um dos seus pilares. Na verdade, como pode qualquer curso de licenciatura secundarizar um nível da educação básica? Hoje, muitos cursos já inseriram, não só um componente curricular que verse sobre a educação infantil, como também um estágio supervisionado, porém, o quadro pouco se alterou, afinal, em muitos destes cursos os professores do estágio não têm domínio sobre os conhecimentos relativos à educação infantil e terminam direcionando a apreensão do conhecimento apenas para uma das dimensões do processo de aprendizagem, que é o desenvolvimento motor.

Em realidade, o desvelamento deste paradoxo levou Sayão (1996, p. 12, grifos originais) a afirmar categoricamente que "a produção teórica destes dois campos quando analisados imbricadamente mostra que não existe uma Educação Física Infantil voltada para as características de aprendizagem e desenvolvimento desta faixa etária". Infelizmente, esta afirmação permanece atual, mesmo tendo sido feita no final do século XX. 
Outro fator que merece destaque em relação à educação física na educação infantil diz respeito aos cursos de formação. Neste caso, como ocorreu na área de conhecimento, também não houve o devido cuidado com as questões referentes à educação da pequena infância. Nesta direção, Sayão (1999, p. 223, grifos nossos) nos auxilia novamente, ao afirmar que "tradicionalmente, não há nos cursos de Licenciatura em Educação Física, uma preocupação em formar professores para intervirem na educação de zero a seis anos." ${ }^{\prime 3}$ Esta constatação de Sayão, referente à formação em educação física para atuar na educação infantil, é percebida a posteriori no discurso de duas outras pesquisadoras,

[...] numa formação com visíveis insuficiências, mostra-se questionável a responsabilidade das Universidades com a sociedade, principalmente, no âmbito do comprometimento em não apenas conferir títulos aos profissionais que forma, mas conferir-lhes uma formação que realmente os capacite a atuar coerentemente às necessidades da parcela da sociedade que visam atender, aqui, no que se refere às crianças. (VIEIRA; WELSH, 2007, p.136).

Esta extravagância se acentua mais ainda quando algumas das licenciaturas espalhadas pelo país incluem um estágio em educação infantil, mas sem nenhum componente curricular que lhe faça a devida interlocução, isso pode ser verificado nas licenciaturas em educação física de algumas universidades estaduais baianas. Ora, se os estágios, de uma forma geral, são extremamente complexos, imagine-se com esse "modelo" que certos cursos de educação física resolveram implementar. Na realidade, parece que esta incorporação da educação infantil funciona muito mais como compensação em vista da negligência que a educação da criança pequena sofreu ao longo de décadas, ao invés de uma compreensão da real necessidade deste conhecimento para a formação do futuro professor.

Entrementes, a partir do momento que a LDBEN 9394/96 definiu a educação física como componente curricular obrigatório de toda a educação básica, o Estado quase que imediatamente trouxe à luz uma proposta articulada, publicada em 1997, nos seus “Parâmetros Curriculares Nacionais: educação física - primeiro e segundo ciclos", insinuando a caracterização deste componente curricular, ali se afirmava que

3 O segmento agora é de 0 a 5 anos, em função da lei ordinária 11.114/2005 alterar os artigos 60, 30, 32 e 87 da LDBEN/9394/96, tornando obrigatório o início do ensino fundamental aos seis anos. 
O documento de educação física traz uma proposta que procura democratizar, humanizar e diversificar a prática pedagógica da área, buscando ampliar, de uma visão apenas biológica, para um trabalho que incorpore as dimensões afetivas, cognitivas e socioculturais dos alunos. Incorpora de forma organizada, as principais questões que o professor deve considerar no desenvolvimento do seu trabalho, subsidiando as discussões, os planejamentos e as avaliações da prática da educação física nas escolas. (BRASIL, 1997, p.15).

Na verdade, há naquela política pública uma preocupação não só em enunciar uma sistematização para além da costumeiramente biológica (estereotipia que marcou a área ao longo de sua história), como também em apontar caminhos para uma implementação extremamente diversificada da educação física no âmbito escolar. Poder-se-ia dizer que há um avanço em relação ao que se tinha; o Estado apresenta uma proposta de intervenção "sistematizada", ainda que se fale de parâmetros.

No que diz respeito ao componente curricular educação física, outros parâmetros vieram à luz, em 1998 e 1999, fechando com isso parte do ciclo da educação básica, já que não há qualquer sinalização para a intervenção na educação infantil. O Estado contemplava, a partir desta política, com certo estardalhaço, algo que sempre fora um problema para área; ou seja, conseguia estabelecer uma organização teórico-metodológica para todas as séries dos ensinos fundamental e médio, ainda que esta decisão tenha sido cercada de críticas, principalmente pelo paradigma escolhido.

Até aqui percebe-se que nem a área nem os cursos de formação, tampouco o Estado, que lançou parâmetros curriculares para todos os níveis (?) da educação básica, apresentaram qualquer proposta de intervenção sistemática que incorporasse a educação física à educação infantil.

Curiosamente, apesar deste cenário nebuloso, há ainda, de forma "marginal" e esporádica, uma educação física na educação infantil como parte integrante da proposta pedagógica de diversas Instituições de educação infantil em cidades como Florianópolis, Porto Alegre, Vitória, Uberlândia, entre outras.

Talvez esta seja, das contradições que perseguem a educação física na educação infantil, a mais contundente: fazer parte da proposta pedagógica das creches e pré-escolas e não ter uma concepção meto- 
dológica que a oriente. Neste caso, certas questões se fazem necessárias: se não há uma proposta elaborada por nenhuma das instâncias mencionadas, em quais pressupostos teórico-metodológicos se sustenta o trabalho pedagógico das cidades mencionadas? As aulas de educação física nestes espaços perspectivam o ensino ou o cuidar/educar? E quem é o profissional que é responsável pelo trabalho pedagógico do componente curricular educação física? No debate aqui desenvolvido, as análises se concentram na primeira das questões norteadoras; isto é, tenta-se demonstrar em quais dos pressupostos teórico-metodológicos da educação infantil a educação física se ancora para a materialização de sua prática pedagógica nas instituições de educação infantil, independentemente de o profissional ser ou não licenciado na área.

\section{Análise do discurso das abordagens metodológicas da educação infantil na educação física}

A educação física na educação infantil, quando existe em determinada rede municipal de Educação, deve recorrer a alguma abordagem metodológica que possibilite as ações pedagógicas dos docentes que a ministram. Qualquer outra percepção cairia no "fazer por fazer", isto é, no senso comum. Se tomarmos como referência a Rede Municipal de Educação de Florianópolis, a primeira a incluir, segundo Wendhausen (2006), o professor de educação física em seus quadros na década de 1980, o cenário não é muito diferente. Na verdade, com a necessidade de fazer parte da proposta pedagógica da instituição da educação infantil, a educação física abre mão dos conteúdos originais, incorporando todo tipo conhecimento, menos os seus. Neste sentido, Mello (2009, p. 265/6) constata que "[...] os professores da disciplina Educação Física continuam procurando legitimá-la não por seu conteúdo específico, mas porque ela pode contribuir para a solidariedade e para a formação da cidadania".

Há outro problema que dificulta o desenvolvimento da educação física na educação infantil, que se relaciona ao fato de ser um componente curricular em instituições (creches e pré-escolas) onde a transmissão de conteúdos, a partir do paradigma hegemônico, é vista como algo impensável. Faria (2005) defende o nível da educação infantil como um espaço onde deve ocorrer o cuidar/educar. Na sua compreensão, toda e qualquer outra proposição sinaliza a antecipação precoce ao 
ensino fundamental. Temos aí o embate teórico-metodológico entre o "Ensino de Conteúdos" versus o "Cuidar/Educar".

Entretanto, transcorridos vinte anos pós-LDBEN 9394/96, a educação física convive na educação infantil com uma crise de identidade infinita e dilemas quase insolúveis.

O primeiro dos dilemas se relaciona à condição de ser um componente curricular obrigatório, mas que não tem uma concepção metodológica que direcione sua prática, em função do embate ensinar versus cuidar/educar.

O segundo dilema é que pode ser ministrada tanto pelo professor de educação física (aquele que tem formação específica) quanto, e principalmente, pelo profissional formado no curso Normal Superior, alocado nos Institutos Superiores de Educação, os remanescentes do antigo magistério e, por fim, pelo de Pedagogia, ainda que os três últimos não tenham se apropriado de qualquer conhecimento em seus currículos sobre o componente curricular educação física, porém o Parecer CNE/CEB 016/2001 Ihes garante esta prerrogativa, argumentando que "proibir ou cercear a atividade docente multidisciplinar em um componente curricular específico implicaria em afrontar os termos da Carta Magna e contrariar uma longa tradição educacional." (BRASIL, 2001, p. 3, grifos nossos).

Note-se o quão paradoxal esta situação se configura. Ora, se mesmo mostrando que os cursos de licenciatura em educação física não conseguem instrumentalizar os futuros professores para que possam atuar satisfatoriamente na educação infantil, o que dizer daqueles profissionais referidos no Parecer?

Espera-se que os cursos de formação inicial e continuada de professores incluam, dentre seus temas de estudo e de prática de ensino, os diversos componentes curriculares, inclusive educação física. A clara dicção do texto constitucional, ao afirmar que a educação obrigatória deve ser de qualidade, implica em garantir que os alunos tenham aulas de todos os componentes curriculares. (BRASIL, 2001, p. 2-3, grifos nossos).

Em síntese, quem dará aulas, inicialmente, de educação física na educação infantil serão ou os egressos dos cursos de Pedagogia ou dos cursos Normal Superior, o que remete à seguinte questão: se a 
educação física não consegue formar para a intervenção na educação infantil, poder-se-ia dizer que os cursos citados, a partir das sugestões do Parecer, o farão? Neste caso, o legislador, ao não levar em consideração estas idiossincrasias, termina por cercear o direito de a criança pequena se apropriar dos conteúdos da educação física, embora haja também precariedade nos cursos quanto à formação para este Nível da Educação.

A observação nos espaços de intervenção docente permite afirmar que existem na educação infantil perspectivas diversas quanto ao encaminhamento do trabalho pedagógico, nada, porém, que tenha um construto elaborado de forma sistemática. Neste caso, é possível evidenciar, entre estas abordagens e na especificidade deste debate, duas que se sobressaem pela contundência de suas posições e que, neste caso, contemplam satisfatoriamente os propósitos desta pesquisa. Ou seja, estas abordagens estabelecem, de forma bem concreta, como se deve realizar o trabalho pedagógico nas instituições de educação infantil. Acrescentaríamos ainda que, ademais, existe um confronto político-ideológico vigoroso, onde duas cosmovisões distintas e antagônicas que se digladiam no sentido de firmar território.

\section{Cuidar/educar versus ensino de conteúdos}

Analisando seus pressupostos teórico-metodológicos, é possível verificar que uma das perspectivas de abordagem segue ostensivamente as orientações daquilo que determina a LDBEN 9394/96, ou seja, a educação infantil compõe com o ensino fundamental e médio os níveis de ensino da educação básica, neste caso, e sem delongas, defende intransigentemente que "as crianças são alunos (aprendizes), e o trabalho pedagógico tem como pilar a transmissão de conhecimentos para revolucionar o desenvolvimento infantil sem perder de vista as peculiaridades do mesmo" (ARCE, 2007, p. 34).

Em sentido oposto, a segunda das abordagens, ancorada nas determinações da política educacional, que definem as creches e pré-escolas como educativas, mas sem caráter escolar, segue o caminho inverso daquelas prescrições, entre elas, a já citada precocidade, entendendo que cuidar/educar é um binômio indissociável que deve nortear as ações didático-pedagógicas nos espaços coletivos de educação, isto é, "a creche e a pré-escola têm como objeto as relações educativas trava- 
das num espaço de convívio coletivo que tem como sujeito a criança de 0 a 6 anos de idade" (ROCHA, 1999, 60, grifos originais).

Em meio a este embate de posições epistemológicas e contendas, cuja pretensão deve ser contribuir na educação da criança pequena, a educação física absorve em sua prática pedagógica, nas instituições de educação infantil, estes vieses, na grande maioria das vezes, acriticamente, afinal, muito do que foi/está sendo elaborado, só muito recentemente vem sendo incorporado aos debates destes profissionais, pela razão pura e simples de que estas problemáticas passam ao largo nos cursos de formação em educação física, infelizmente, a apropriação desta discussão só poderá acontecer quando da inserção destes professores em cursos de formação continuada, na verdade, se estes acontecerem. Nesta direção, a problemática tem o escopo de analisar como cada uma delas se organiza em seus fundamentos teórico-metodológicos e como o professor de educação física, em sua prática pedagógica na educação infantil, incorpora estes elementos que lhe fora/é negligenciado no curso de formação.

Em verdade, inserir estas abordagens neste debate sobre a formação de professores em educação física, cujo espaço de atuação é/será o nível da educação infantil, se justifica por duas razões. A primeira (de ordem didático-pedagógica) está atrelada ao parágrafo $3^{\circ}$ do Art. 26 da LDBEN 9394/96, quando este enuncia que a educação física deve estar "integrada à proposta pedagógica da escola" (BRASIL, 1996, p. 27); a segunda (de ordem curricular) também ancorada no mesmo artigo, por indicá-la como "componente curricular obrigatório da educação básica" (BRASIL, 1996, p. 27). Em razão destas peculiaridades, entende-se como imprescindível, para a discussão que se trava, colocá-las em evidência, justamente porque estas abordagens deverão estar atreladas à proposta pedagógica dos espaços de atuação, como também irão definir o perfil do professor e do processo de articulação do componente curricular educação física nas ações pedagógicas nos espaços coletivos de educação.

A perspectiva de abordagem orientada, entre outros, por Cerisara (2007), Faria (2005), Nascimento (2007) e Rocha (1999, 2008, 2011) advoga que a educação infantil não pode e nem deve ser espaço de antecipação precoce de "transmissão de conteúdos" como preparação para o nível subsequente à educação infantil, ou seja, a educação infantil não deve servir como uma preparação articulada ao ensino fundamental. Na realidade, este aspecto será firmemente defendido pelo grupo 
delineado, em razão de se compreender que "o trabalho com crianças pequenas em contextos educativos deve assumir a educação e cuidado enquanto binômio indissociável e não o ensino" (CERISARA, 2007, p. 28, grifos nossos). Não resta dúvida que se trata de uma demarcação de posição. Neste caso, emerge, nos interstícios do discurso, o perfil do professor que orienta esta perspectiva metodológica.

Observa-se que, neste horizonte epistemológico, talvez seja esta a principal preocupação, das muitas que se insurgem na educação infantil, entre os estudiosos desta abordagem, ou seja, garantir que a criança pequena não seja submetida ao padrão da escola regular precocemente, tendo tempo, oportunidade e possibilidade de vivenciar outras formas de apreensão da realidade diferentes daquelas da escola formal. Como não poderia ser diferente o modelo do ensino fundamental parece rondar, como um fantasma, as Instituições de educação infantil, fazendo com que as autoras rechacem quaisquer indicações nesta direção, o que denota coerência com seus pressupostos epistemológicos.

\begin{abstract}
Educar e cuidar são objetivos da educação infantil, assim colocados para dar ênfase na centralidade da criança e na sua especificidade em relação ao ensino escolar. O que não quer dizer que a creche e a pré-escola também não tenham o objetivo, como a escola, de reproduzir e coagir, e também de transformar e libertar e, como toda educação, tem sempre o objetivo de cuidar. Também não quer dizer que a educação nestas instituições não tenha conteúdo, seja espontaneísta, só porque nelas não se trabalha com conteúdos escolares e o professor não ministra as disciplinas escolares formais: o professor é um professor de crianças. (FARIA, 2005, p. 1021-2, grifos originais).
\end{abstract}

Em relação à questão de ser espontaneísta ou não, nunca é demais lembrar que o RCNEI - Referencial Curricular Nacional para a educação infantil tem como eixo articulador do trabalho pedagógico o prazer e a espontaneidade, política pública esta referendada pelas pesquisadoras da abordagem em destaque, em período anterior. "Ao nosso ver, ele é uma importante iniciativa do MEC." (PALHARES, MARTINEZ, 2007, p. 8). A defesa dos princípios evidenciados, por esta abordagem, vem de longa data e foi preciso muito esforço para garantir que as crianças fossem consideradas cidadãos de direitos, nesta trajetória, antes das pequenas conquistas, foi travado um diálogo de "surdos" por muito tempo com as 
instâncias responsáveis pelas políticas públicas direcionadas à educação infantil.

Aqueles eram anos de luta em torno da Constituição da República Federativa do Brasil, que aprovada em 05 de outubro de 1988, foi a primeira a afirmar o direito das crianças à educação infantil em creches e pré-escolas. (BRASIL, 2009, p. 6).

Não por acaso, por muito tempo o espaço de educação da criança pequena foi tratado como "terra de ninguém", onde toda e qualquer formação profissional por sua especificidade entendia que deveria estar presente, a educação física entre elas. Some-se a isso, o tratamento dispensado à educação infantil na legislação que antecedeu à promulgação da Constituição de 1988, assim como "os estudos e as pesquisas sobre a escola por bastante tempo negligenciaram a educação das crianças pequenas." (FARIA, 2005, p. 1018).

Com um longo tempo acumulado de debates, entremeados com a edição da terceira lei de diretrizes e as reformas que trouxeram no seu rastro documentos como o RCNEl, entre tantos outros importantes pelo conteúdo e significado, levaram as referências desta abordagem a articular propostas que pudessem dar um encaminhamento às práticas pedagógicas nas creches e pré-escolas, ancoradas em um arcabouço teórico que assegurava que a "experiência e a formação cultural de crianças e adultos são marcas que devem nortear as propostas pedagógicas de educação infantil, as práticas cotidianas e os projetos de formação de professores" (BRASIL, 2009, p. 15). Como havia a preocupação em que a proposta terminasse por impor limites à orientação do coletivo das creches e pré-escolas, por esta razão, as linhas mestras foram enunciadas a partir do entendimento de que

A responsabilidade de dirigir o desenvolvimento da ação educativa envolve, para nós, um compromisso com o desenvolvimento e a aprendizagem das crianças a partir da ampliação das experiências próximas e cotidianas em direção à apropriação de conhecimentos no âmbito mais ampliado e plural, porém, sem finalidade cumulativa ou com caráter de terminalidade em relação à elaboração de conceitos. (ROCHA, 2008, p. 2).

A síntese em relação à proposição não ser coercitiva no encaminhamento das ações nos espaços de educação coletiva é eviden- 
ciada na afirmação: "uma pedagogia comprometida com a infância necessita definir as bases para um projeto educacional-pedagógico para além da aplicação de modelos e métodos. (ROCHA, 2008, p. 3, grifos originais). Há ainda a preocupação óbvia, mas pertinente, com o sujeito a quem esta ação pedagógica é direcionada, "não aceitar a ideia de uma aceleração artificial do desenvolvimento psíquico infantil e aceitar a concepção da psicologia e pedagogia de fazer nesta etapa a ampliação e o enriquecimento deste desenvolvimento" (HURTADO apud ROCHA, 2008, p. 8). Imbuída deste propósito, a pesquisadora defende que necessariamente o que deve ser desenvolvido nas creches e pré-escolas é

[...] o enriquecimento de experiência comunicativa da criança com adultos e coetâneos e a realização de atividades, que, além de dar-lhes prazer, contribuam para seu desenvolvimento e enriquecimento intelectual, como são o jogo, a construção, o desenho, as atividades plásticas e criativas em geral (HURTADO apud ROCHA; KRAMER, 2011, p. 379-380).

Como é possível perceber, pelos espaços temporais em que a pesquisadora transita, esta proposta para a educação infantil vem se constituindo e é no confronto com o cotidiano que acontece sua reelaboração constante. Por fim, e no sentido de assegurar uma percepção de conjunto de todo o processo, que se realize a

[...] observação permanente e sistemática, o registro e a documentação como forma de avaliar o proposto, conhecer o vivido e replanejar os campos de experiências a serem privilegiados e as formas de organização dos espaços, dos tempos e dos materiais. (ROCHA, 2008, p. 9).

Eis de forma objetiva aquilo que a primeira das abordagens destacadas acredita ser significativo para a sistematização/avaliação do trabalho pedagógico nas instituições de educação infantil. Talvez fosse necessário dizer que a perspectiva assinalada não é um "coletivo", no sentido estrito; ou seja, não está se dizendo que em certo dia, tempo e lugar determinados, as autoras tenham se reunido no intuito de elaborar uma proposta teórico-metodológica para a educação infantil. Fala-se em abordagem pela aproximação que têm em relação à concepção pedagógica que acreditam e no projeto histórico que defendem. 
A segunda perspectiva de abordagem tem seus pressupostos sintetizados, em 2007, sob a organização de Arce e Martins, na obra Quem tem medo de ensinar na educação infantil? - em defesa do ato de ensinar. As proposições contidas na obra têm a pretensão de "fornecer subsídios para a elaboração de Projetos Políticos Pedagógicos para a E.l. comprometidos com a socialização do patrimônio cultural humano e a serviço do desenvolvimento histórico-cultural das crianças pequenas." (ARCE et al, 2007, p. 7-8). Estabelece como princípio norteador que, fundamentada na Constituição de 1988 e na LDBEN 9394/96, a educação infantil, o ensino fundamental e o ensino médio são um todo articulado, portanto, a educação infantil neste aspecto é um espaço de ensino, no stricto sensu. Quanto a isso, é entusiástica a manifestação de Dermeval Saviani (na orelha do livro), "Já era hora, portanto, de se ultrapassar as hesitações que separavam a educação das crianças pequenas, dita pré-escolar, daquela desenvolvida nas escolas para os meninos e meninas a partir dos 7 anos de idade." Perceptível neste discurso é a ideia de se enunciar algo em gestação como se já estiveste estabelecido, deixando de fora as polêmicas que cercam o debate, o "já era hora" não deixa qualquer dúvida sobre a intenção do pesquisador.

Em relação ao que a educação infantil se constituiu ao longo do tempo, há uma crítica radical ao modelo que vigora atualmente e uma indicação de que é preciso buscar outras alternativas de intervenção, sugerindo que as que vêm sendo implementadas marcadas pela educação em parceria com as famílias (um projeto doméstico), constituem-se em uma política para a educação infantil não formal e de baixo custo, a compreensão é que os modelos que vêm sendo utilizados não atendem às prescrições do que deveria ser o trabalho pedagógico para a população infantil.

Avançamos no século $X X$, iniciamos o século XXI e até o presente a educação infantil em nosso país não se destituiu destas marcas, bem como não se firmou, de fato, como expressão do direito educacional das crianças de zero a seis. Ou seja, os modelos de educação infantil até agora implementados não são representativos daquilo que deveria ser o trabalho educativo com esta faixa etária, legado histórico que se expressa nas frágeis expectativas educacionais que se têm a respeito. (ARCE; MARTINS, 2007, p. 6) 
Está no âmago do discurso desta abordagem a defesa intransigente do papel do professor como o responsável pela transmissão do conhecimento (este elemento, além de caracterizar firmemente o antagonismo dos projetos, é a principal das divergências entre as abordagens). Rememorando as práticas assistencialistas, que marcaram de forma decisiva a educação infantil em sua trajetória, a abordagem sinaliza "o risco de sua subjugação a modelos pedagógicos anti-escolares, desqualificadores da transmissão dos saberes clássicos passíveis de aprendizagem por esta faixa etária." (ARCE, MARTINS, 2007, p. 6).

Fala-se em antagonismo, ainda que o conflito seja "silenciado", ao defender a premissa da transmissão de conhecimento, o escopo é garantir que o professor assuma como responsabilidade essencial o ato de ensinar, nesta direção, o eixo articulador da educação infantil é o ensino, como vimos, a criança é um estudante, rechaçando a aprendizagem ancorada no prazer e nas experiências realizadas espontaneamente.

\begin{abstract}
Obviamente que a transmissão deste saber erudito se adequará à especificidade da faixa etária com a qual se trabalha. Não se procurará ensinar equações do segundo grau para crianças de 5 anos, ou se tentará ensinar adição com dezenas a bebês de 4 meses. (ARCE, 2007, p. 34, grifos nossos)
\end{abstract}

Como já explicitado, o pilar de sustentação para que a abordagem proponha acabar com qualquer distinção em relação à educação infantil e os outros níveis de ensino é a Constituição e a LDBEN, entretanto se observa que não há qualquer sinalização sobre o ponto de atrito que existe entre as leis que sustentam o discurso da abordagem e a política educacional que estabelece creches e pré-escolas como espaço de educação sem caráter escolar, logo, parte-se do seguinte princípio: se a lei é soberana, cabe às instituições cumpri-la, nesta direção, reitera que

[...] a educação e o ensino (apropriação) são formas universais de desenvolvimento psíquico humano (Davidov, 1988, p. 57). A instituição de educação infantil não pode furtar-se ao trabalho intencional que leve a este desenvolver, a este reproduzir, a este apropriar-se do humano. (ARCE, 2007, p. 35, grifos nossos)

Quando se propõe uma concepção metodológica para um nível de educação com faixas etárias tão distintas e nada homogêneas (não 
podemos esquecer que existem bebês no conjunto das faixas etárias que estas abordagens atendem ou pretendem atender) não se pode esquecer a complexidade que isso acarreta. Em relação às faixas etárias, há um aspecto nesta perspectiva, presente também em Sayão (1996), que é a escolha das crianças de 4 a 6 anos. Qual teria sido o motivo que levou o grupo a fazer esta escolha, por que não se incluiu as crianças de zero a três anos na proposta se os estudos mostram que é a faixa etária em que estudos e pesquisas estão em estágio mais incipiente?

Todavia, mesmo com a escolha da abordagem por crianças maiores, esta corre riscos que são inevitáveis em razão da diversidade das crianças envolvidas. Na realidade, a questão que se coloca é: como atender de forma equânime a uma população tão diversa, sem cair na armadilha da receita pronta e mecânica, se a perspectiva é que se está elaborando algo para o acesso de "sujeitos ideais"? Neste momento, o "como fazer" é posto à prova. Como fazer para que o que foi pensado aconteça de forma satisfatória? As questões se remetem à viabilidade do processo metodológico anunciado. Será ele capaz de traduzir fielmente aquilo que foi planejado visando à transmissão de conhecimento às crianças na prática pedagógica sugerida?

O professor aqui planeja antes de entrar em sala, prepara-se estudando os conteúdos, desenvolvendo estratégias de ensino e buscando metodologias eficazes para a aprendizagem. Enfim ele sabe que o desenvolvimento de suas crianças será marcado pelo seu trabalho intencional em sala de aula. Desde o momento em que entra na escola, o professor tem plena consciência de que precisa estar $100 \%$ com as crianças, que suas atitudes, sua fala reverbera na humanização das crianças sob sua responsabilidade. (ARCE, 2007, p. 35)

Neste caso, vemos o modelo formatado da segunda perspectiva de abordagem e como seus interlocutores pretendem materializá-lo. Por alguma razão, não explicitada, as articuladoras da proposta apresentam uma justificativa em relação à novidade que trazem para a área da educação infantil, "salientamos que o caminho ainda está em construção, pois a nossa proposição é nova dentro da área, que sempre foi marcada por um caráter oposto ao trabalho escolar." (ARCE, 2007, p. 35).

É preciso reafirmar que os riscos existem e não são poucos. Não se pode dizer por que o processo é diretivo. Aqui o professor assume a 
direção das ações pedagógicas, que está garantido que será diferente do modelo não-diretivo da abordagem anterior. Dito de outra maneira, sabem-se dos problemas da apreensão do conhecimento por parte dos estudantes nos outros níveis de ensino, ainda que esteja garantida a presença do paradigma de ensino sugerido pela segunda das abordagens.

Contudo, não há dúvida que esta perspectiva valoriza o trabaIho do professor, dando-lhe possibilidade de não ser coadjuvante em sua prática pedagógica, papel que representa na primeira perspectiva apresentada. Deixar que a criança seja ela mesma é a solicitação feita ao professor, na primeira das abordagens. Neste caso, o professor se transforma "no parceiro mais experiente por excelência, cuja função é propiciar e garantir um ambiente rico, prazeroso, saudável e não discriminatório de experiências educativas e sociais variadas" (BRASIL, 1998, p. 30). Nesta lógica, para ser parceiro das experiências das crianças não há necessariamente de se ter uma formação acadêmica, de ser professor no stricto sensu. Convenha-se que se uma política pública como o RCNEI sugere ao professor de educação física que

\begin{abstract}
[...] tenha consciência que na brincadeira as crianças recriam e estabilizam aquilo que sabem sobre as mais diversas esferas do conhecimento, em uma atividade espontânea e imaginativa. Nesta perspectiva não se deve confundir situações nas quais se objetiva determinadas aprendizagens relativas a conceitos, procedimentos ou atitudes explícitas com aquelas nas quais os conhecimentos são experimentados de uma maneira espontânea e destituída de objetivos imediatos pelas crianças. Pode-se, entretanto, utilizar os jogos, especialmente aqueles que possuem regras, como atividades didáticas. É preciso, porém, que o professor tenha consciência que as crianças não estarão brincando livremente nestas situações, pois há objetivos didáticos em questão. (BRASIL, 1998, p. 29, grifos nossos).
\end{abstract}

Neste caso, a instituição de educação infantil passa a ser uma extensão da casa da criança, propõe-se ali que um dos conteúdos da educação física, o jogo, não seja usado com fins didático-pedagógicos, o professor deve ser cuidadoso quanto a isso em sua prática pedagógica. Nestes termos, a questão que precisa ser formulada é: para qual das abordagens metodológicas deve ser orientada a formação 
de professores em educação física cujo campo de atuação é a educação infantil?

\section{Considerações finais}

Por tudo o que foi visto, não cabe conciliação entre as perspectivas. Elas se antagonizam em todos os seus pressupostos. $O$ choque entre a abordagem que entende as creches e pré-escolas como espaço do educar/cuidar e a que assevera que ali é lugar de ensino, faz com que a educação física perca sua identidade, tornando-se tudo, menos educação física.

Na primeira, o professor de educação física torna-se apenas um "animador", caso seja ele o interlocutor entre a criança e o saber, precisando ter o cuidado para não interferir no eixo prazer/espontâneo, caso queira dar um cunho didático às suas atividades.

Por outro lado, tampouco consegue se aproximar daquela que justifica a inserção do ensino na educação da criança pequena, justamente porque não se apropria no curso de formação de instrumentos que the permitam organizar didaticamente os conteúdos do componente curricular do qual é um "especialista".

Entretanto, é preciso ressaltar, a segunda abordagem reinsere o professor de educação física na educação dos indivíduos de pouca idade ao Ihes garantir trabalhar com seus conteúdos específicos, não lhes impondo qualquer empecilho. Como isso não vai acontecer "naturalmente", é preciso que os cursos de licenciatura em educação física reavaliem seu processo de formação, sem barganhas, instrumentalizando de forma objetiva o profissional para atuar no nível da educação infantil.

\section{Referências}

ARCE, Alessandra; MARTINS, Lígia Márcia (orgs.) et al. Quem tem medo de ensinar na educação infantil?- em defesa do ato de ensinar. Campinas: Alínea, 2007.

ARCE, Alessandra. O Referencial Curricular Nacional para a educação infantil e o espontaneísmo: (Re)colocando o ensino como eixo norteador do trabalho pedagógico com crianças de 4 a 6 anos. In: ARCE, Alessandra; MARTINS, Lígia Márcia (orgs.) et al. Quem tem medo de ensinar na educação infantil?-em defesa do ato de ensinar. Campinas: Alínea, 2007. 
BRASIL. Medida Provisória n 746, de 22 de setembro de 2016. Institui a Política de Fomento à Implementação de Escolas de ensino médio em Tempo Integral, altera a Lei no. 9.394, de 20 de dezembro de 1996, que estabelece as diretrizes e bases da educação nacional, e a Lei $n^{\circ}$. 11.494 de 20 de junho 2007, que regulamenta o Fundo de Manutenção e Desenvolvimento da Educação Básica e de Valorização dos Profissionais da Educação, e dá outras providências.

. Ministério da Educação. Lei de Diretrizes e Bases da Educação Nacional. Lei $n^{\circ}$. 9.394/96, de 20 de dezembro de 1996. Estabelece as diretrizes e bases da educação nacional. Brasília, DF, 1996.

- Ministério da Educação. Lei de Diretrizes e Bases da Educação Nacional. Lei $n^{\circ}$. 4.024, de 20 de dezembro de 1961. Estabelece as diretrizes e bases da educação nacional. Brasília, DF, 1961.

. Ministério da Educação. Lei de Diretrizes e Bases da Educação Nacional. Lei $n^{\circ}$.5.692, de 11 de agosto de 1971. Estabelece as diretrizes e bases da educação nacional. Brasília, DF, 1971.

- Ministério da Educação. Parâmetros Curriculares Nacionais: educação física (PCNEF). Brasília: MEC/SEF, 1997.

- Ministério da Educação. Referencial Curricular Nacional para educação infantil. Brasília: MEC/SEF, 1998 3v.: II. Volume 1: Introdução.

. Ministério da Educação. Conselho Nacional de Educação. Parecer CNE/CES 016/2001, de 21 de novembro de 2001. Brasília-DF. - Instituto Nacional de Estudos e Pesquisas Educacionais Anísio Teixeira. Estudo exploratório sobre o professor brasileiro com base nos resultados do censo escolar Educação Básica de 2007. Brasília: INEP, 2009.

CERISARA, Ana Beatriz. A produção acadêmica na área de educação infantil a partir da análise de pareceres sobre o Referencial Curricular Nacional da educação infantil: primeiras aproximações. In: FARIA, Ana Lúcia Goulart; PALHARES, Marina Silveira (orgs.). Educação infantil Pós - LDB: rumos e desafios. 6. ed. revista. Campinas: Autores Associados FE/ UNICAMP; São Carlos: Editora da UFSCAR; Florianópolis: Editora da UFSC, 2007. p. 19-49 (Coleção Polêmicas do nosso Tempo; 62). 
ELKONIN, Daniil B. Psicologia do Jogo. São Paulo: Martins Fontes, 1998

FAIRCLOUGH, Norman. Discurso e mudança social. Brasília: Editora Universidade de Brasília, 2001.

FARIA, Ana Lúcia Goulart de. Políticas de Regulação, Pesquisa e Pedagogia na educação infantil, primeira etapa da educação básica. Educação e Sociedade, v. 26, n. 92, p. 1013-1038, especial, out. 2005.

LEONTIEV, Alexis. O desenvolvimento do psiquismo. São Paulo: Editora Moraes, 2002

MELLO, Rosângela Aparecida. A necessidade histórica da educação física na Escola: a emancipação humana como finalidade. 2009. Tese (Doutorado em Educação) - UFSC. Florianópolis.

NASCIMENTO, Maria Evelyna P. do. Os profissionais da educação infantil e a nova Lei de Diretrizes e Bases da Educação Nacional. In: FARIA, Ana Lúcia Goulart; PALHARES, Marina Silveira (Orgs). Educação Infantil Pós - LDB: rumos e desafios. $6^{\mathrm{a}}$ ed. revista. Campinas: Autores Associados FE/ UNICAMP; São Carlos: Editora da UFSCAR; Florianópolis: Editora da UFSC, 2007. (Coleção Polêmicas do nosso Tempo; 62)

PALHARES, Marina Silveira; MARTINEZ, Cláudia Maria Simões. A educação infantil: uma questão para o debate. In: FARIA, Ana Lúcia Goulart; PALHARES, Marina Silveira (Orgs). Educação Infantil Pós - LDB: rumos e desafios. $6^{\text {a }}$ ed. revista. Campinas: Autores Associados FE/UNICAMP; São Carlos: Editora da UFSCAR; Florianópolis: Editora da UFSC, 2007. (Coleção Polêmicas do nosso Tempo; 62)

ROCHA, Eloísa A. C.; KRAMER, Sonia (Orgs.). Educação Infantil: enfoques em diálogo. Campinas: Papirus, 2011.

ROCHA, Eloísa A. C. Diretrizes Educacionais Pedagógicas para a educação infantil. Prelo Gráfica\& Editora: Florianópolis, 2010.

- A Pesquisa em educação infantil no Brasil: trajetória recente e perspectiva de consolidação de uma pedagogia. 1999. Tese (Doutorado em Educação) - UNICAMP. Campinas.

SAYÃO, Deborah Thomé. Educação física na pré-escola: da especialização disciplinar à possibilidade de trabalho pedagógico. 1996. Dissertação (Mestrado em Educação) - UFSC. Florianópolis. 
. Educação física na educação infantil: riscos, conflitos e controvérsias. Motrivivência, Santa Catarina, v. 11, n. 13, p. 221-238, novembro, 1999.

SHIROMA, Eneida O.; CAMPOS, Roselane F.; EVANGELISTA, Olinda. Técnicas e procedimentos para análise conceitual de documentos de política educacional. In: SHIROMA, E. O. (org.). Uma metodologia para análise conceitual de documentos sobre política educacional. EED/ UFSC/GEPETO, 2004. (Relatório de Pesquisa)

VIEIRA, Carmen Lúcia Nunes; WELSCH, Nadége Luise N. de Abreu. O lugar da infância e da formação humana na formação inicial em educação física. Motrivivência, Santa Catarina, v. 19, n. 29, p. 129-140, dezembro, 2007.

VYGOTSKY, L. S. A Construção do Pensamento e da Linguagem. São Paulo: Martins Fontes, 2001.

WALLON, Henri. A evolução psicológica da criança. São Paulo: Martins Fontes, 2007.

WENDHAUSEN, Adriana Maria P. 0 processo de formação continuada dos professores de educação física que atuam na educação infantil no município de Florianópolis: 1993-2004. 2006. Dissertação (Mestrado em Educação) - UFSC. Florianópolis.

Recebido em dezembro/2016

Aceito em março/2017 